\title{
TREE-MARKING FOR SELECTION CUTTING
}

\author{
BY R. S. JOHNSON
}

Mersey Paper Company, Limited, Liverpool, Nova Scotia

W ITH the proclamation of the Small Tree Conservation Act in Nova Scotia, limiting the cutting of spruce, hemlock and pine to a minimum stump diameter of ten inches inside the bark, one foot above the ground, the Mersey Paper Company decided to conduct its forest operations on the basis of selection cutting in stands which are adaptable to this type of cutting. In the interests of economy in logging, in order to salvage the overmature and defective trees on the areas being logged and to get the maximum production per acre in the first cut, this selection cutting is intended to remove the maximum allowable softwood volume without resultant excessive windfall in the residual stands.

The Indian River area of the Company's holdings is approximately 30,000 acres, mostly well wooded. A small part of this area was clear-cut in 1932-33 and nearly 80,000 cords were removed by clear-cutting in the years 1942-45. Softwood reproduction follows clear-cutting but where spruce comprised over 70 per cent of the stands cut the new growth is about 75 per cent balsam. The remaining forest to be cut selectively is approximately 67 per cent red spruce, 2 per cent black spruce, 9 per cent balsam, 14 per cent hemlock, 1 per cent white pine, and 7 per cent hardwood.

Most of the tract is covered by an all-aged forest partially cut for large spruce and pine from 1876 to 1910 . Most of the hemlock is now overmature as well as a large percentage of the spruce, balsam and hardwood. The balsam is mostly affected by the woolly aphid and the birch, which comprises about 70 per cent of the hardwood in this district, is affected by die-back. Probably 15 per cent of the birch is dead and another 25 per cent is dying. About 3,000 acres are covered by young stands of merchantable sized wood.

The country is of a rolling nature with moderate to steep slopes. The soil, generally well drained, is mostly shallow, of granitic origin with occasional outcroppings of bed rock and generally strewn with granite boulders. In spite of the shallow soil the trees appear to be fairly windfirm, particularly where the boulders are numerous.

Excepting balsam, trees to be cut are marked on the basis of judgment by the marker who endeavours to mark so that, as nearly as possible, 40 per cent of the total merchantable volume of the stand will be cut. The balsam is not marked but all of it is to be cut. In most stands of the type to be cut selectively this species comprises not over 15 per cent of the volume. The hardwoods, not utilized by this Company, are left for wind protection in the residual stands. 
In marking, three classes of trees are recognized as follows:

1. Salvage trees--those which have some visible defect such as rot, mechanical injury, or deformity.

2. Wolf trees-those which have a large spreading crown.

3. Crop trees-the tallest and largest trees in the stand.

The trees to be marked are considered in the above order. Where there are no salvage or wolf trees, the largest tree out of every three large trees in the stand is marked, ignoring the smaller ones. If there are salvage or wolf trees, they are marked in place of the crop trees.

The marking is done with an Alemite Spring Spray Gun equipped with a solid oil-stream nozzle with some slight alterations as described in an article by $A$. W. Bratton and R. H. Ferguson in the Journal of Forestry, 43: 113. 117. The best results have been obtained with $\mathrm{B}$. \& $\mathrm{H}$. quick-drying log paint, bright red, in a mixture of equal parts of kerosene and paint. Marking in freezing weather has been found unsuccessful due to clogging of the gun.

Trees are marked with a spot from four to six feet above the ground and with another spot below the top of the root swell for checking purposes following cutting operations. An experienced marker can mark about 100 cords per day in stands of the type found in the Indian River area.

Tables III to VIII which follow, compiled from tallies taken on sample areas, indicate the results of the marking in detail. The summaries of the samples show 47.6 per cent of the total volume marked in the softwood type, 45.2 per cent in the mixedwood, 43.9 per cent in the young softwood, 21.9 per cent in the young mixedwood, and 40.8 per cent in the swamp type. According to the "Guide for Cutting Red Spruce", by the United States Forest Service a 50 per cent removal may be undertaken with safety on welldrained soils but not over 40 per cent on moister soils. On this basis the percentages marked in this operation are generally within the limit of safety although mostly somewhat higher than the objective of 40 per cent. To reduce the percentage removal, choppers are instructed to leave standing all spruce, pine and hemlock trees $10^{\prime \prime}$ D.B.H. and under in the all-aged and old growth stands and $9^{\prime \prime}$ D.B.H. and under in the young stands marked or not. This reduction amounts to only about one per cent of the total volume in most cases. Little or no marking is done along lake margins, roads, or the margins of other openings in the forest.

Logging is done on the basis of cutting 8,12 , and 16 -foot logs, skidding and yarding. It is found necessary to cut some unmarked trees for yard sites, haul roads and, occasionally, in the process of felling marked trees. Inspection of areas cut by this system has indicated the percentage of unmarked volume cut to be remarkably small. The areas which have been cut-over have fairly uniform residual stands generally and in only three cases were patches noted which were considered to have been cut too heavily. These were not large openings, being from two to four acres. One of these, adjacent to an area clear-cut in 1945.46, is now being clear-cut in order to salvage the residual trees which would probably have been lost to wind had they been left. 
Acreages totalling 2,102.8 acres, and estimated volumes amounting to a total of 25,000 cords, on areas marked in 1946 are shown by camps and forest types in Table I following. Table II shows the cost of marking, totalling 11.8c. per cord. According to the estimates, 85.5 cords were marked per man-day, including lost time.

When selective cutting was started considerable antagonism was found among the choppers and logging personnel. The cutting was done on piece work basis, the same price being paid for selective cutting as was being paid for clear-cutting on this and other operations. At first a comparatively small number of choppers were willing to try selective cutting and found that their pay was as much as or more than they had earned on the clear-cutting basis. This news soon got around among other men and now choppers would rather cut selectively than otherwise.

The hauling is now being done and while comparative cost figures have not been compiled there is little doubt that hauling costs will be about the same as under clear-cutting. However, yarding costs are probably increased slightly and the cost of roads will no doubt show material increase. The cost of camps per cord will also be higher than under clear-cutting.

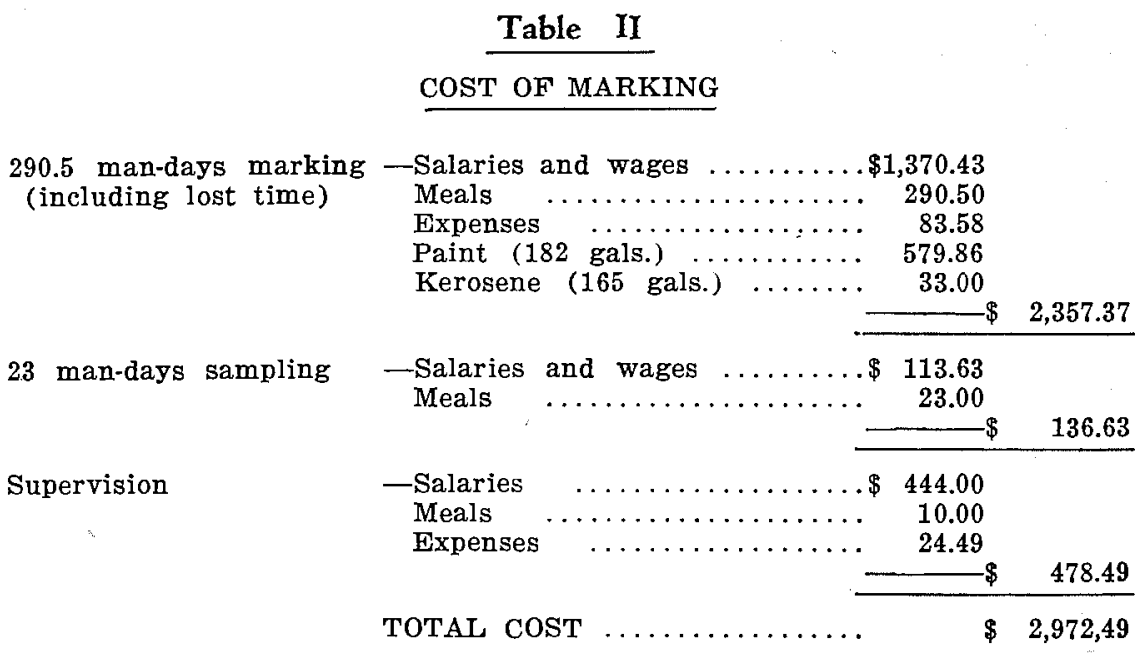

86.1 cords marked per man-day, including lost time.

Cost per cord:

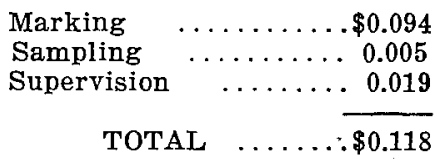




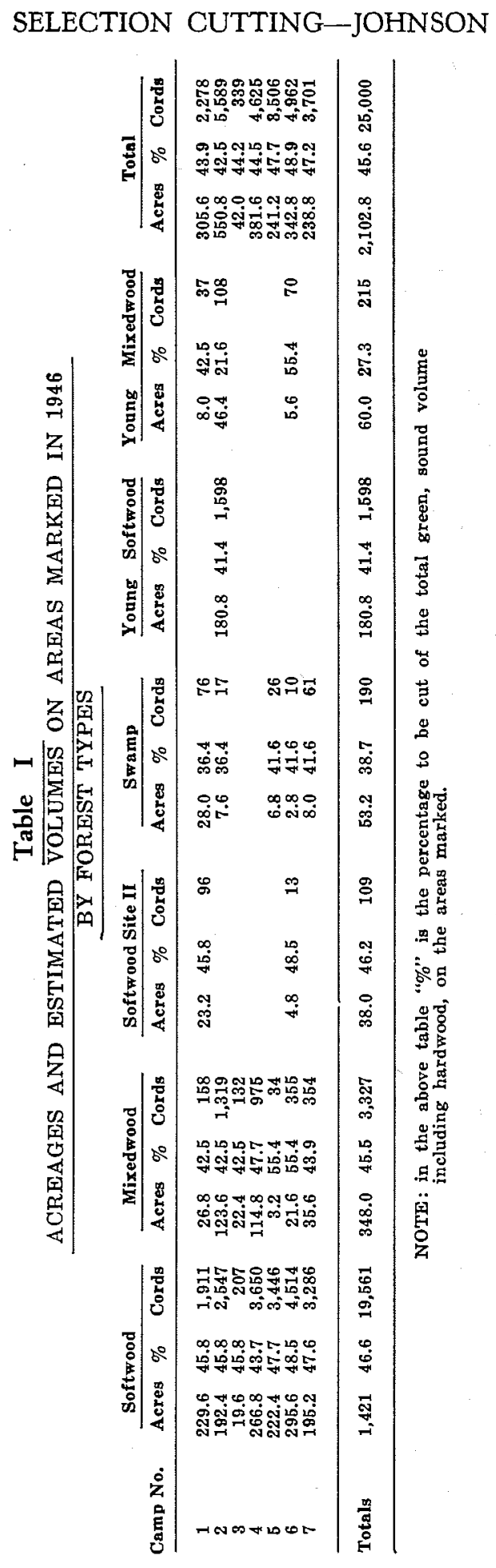




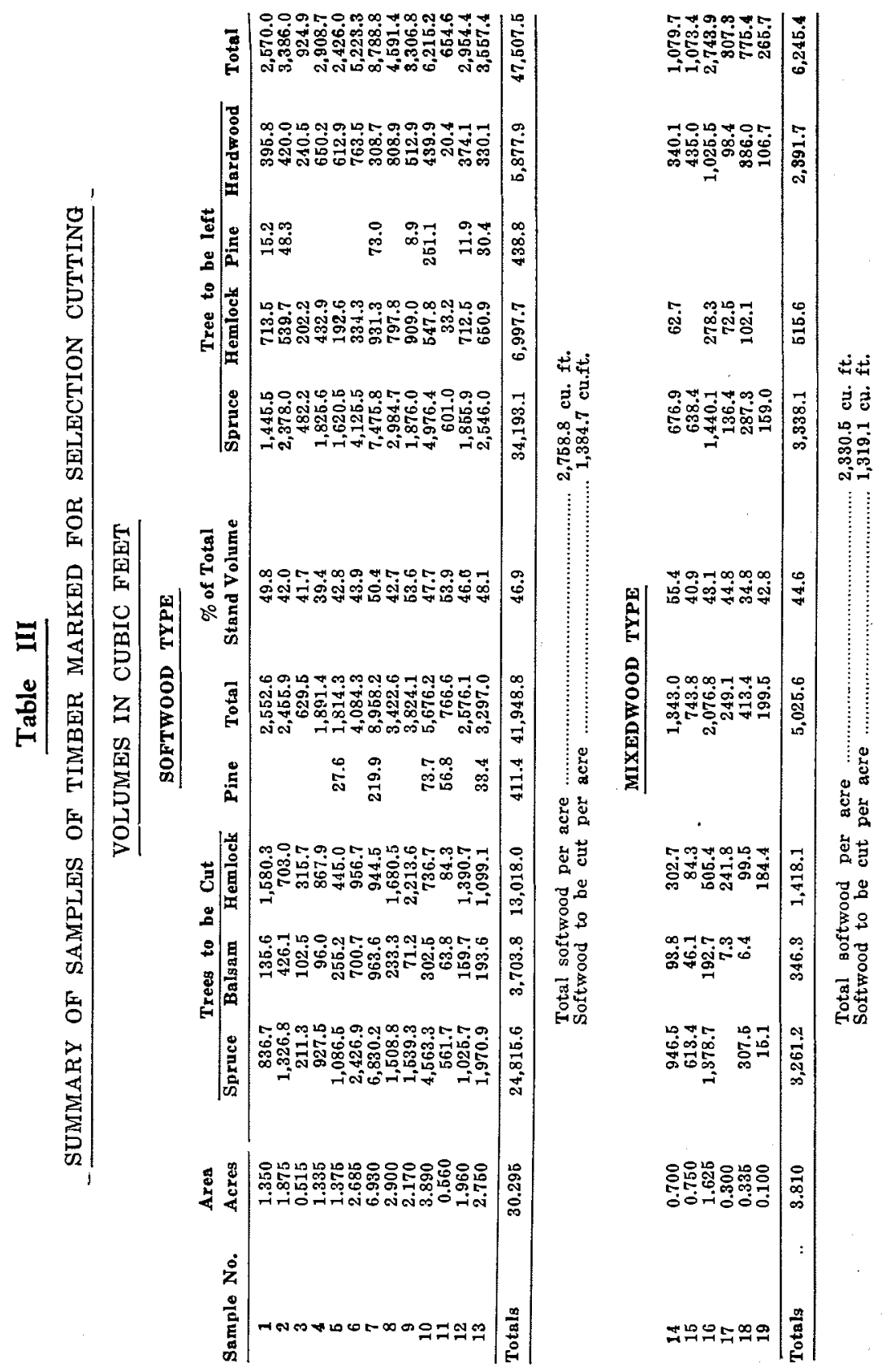




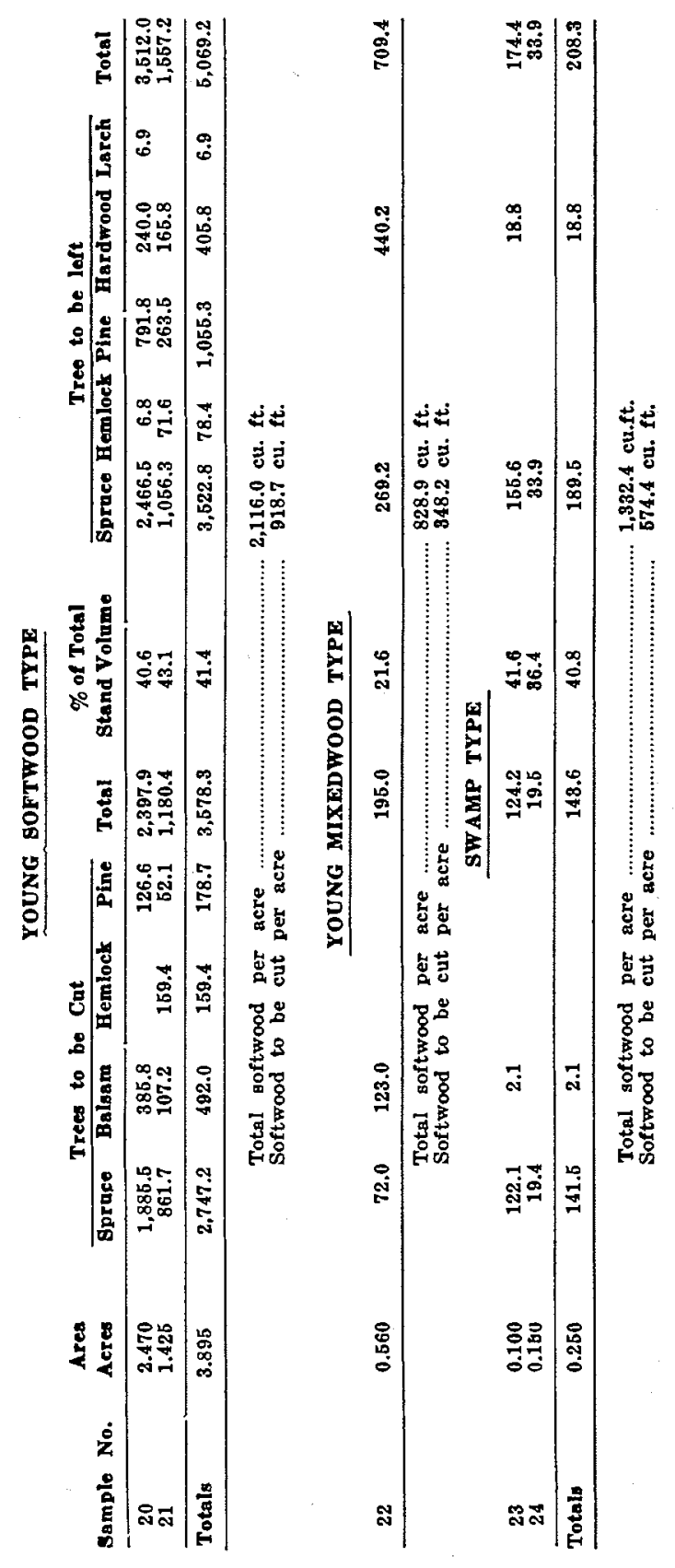




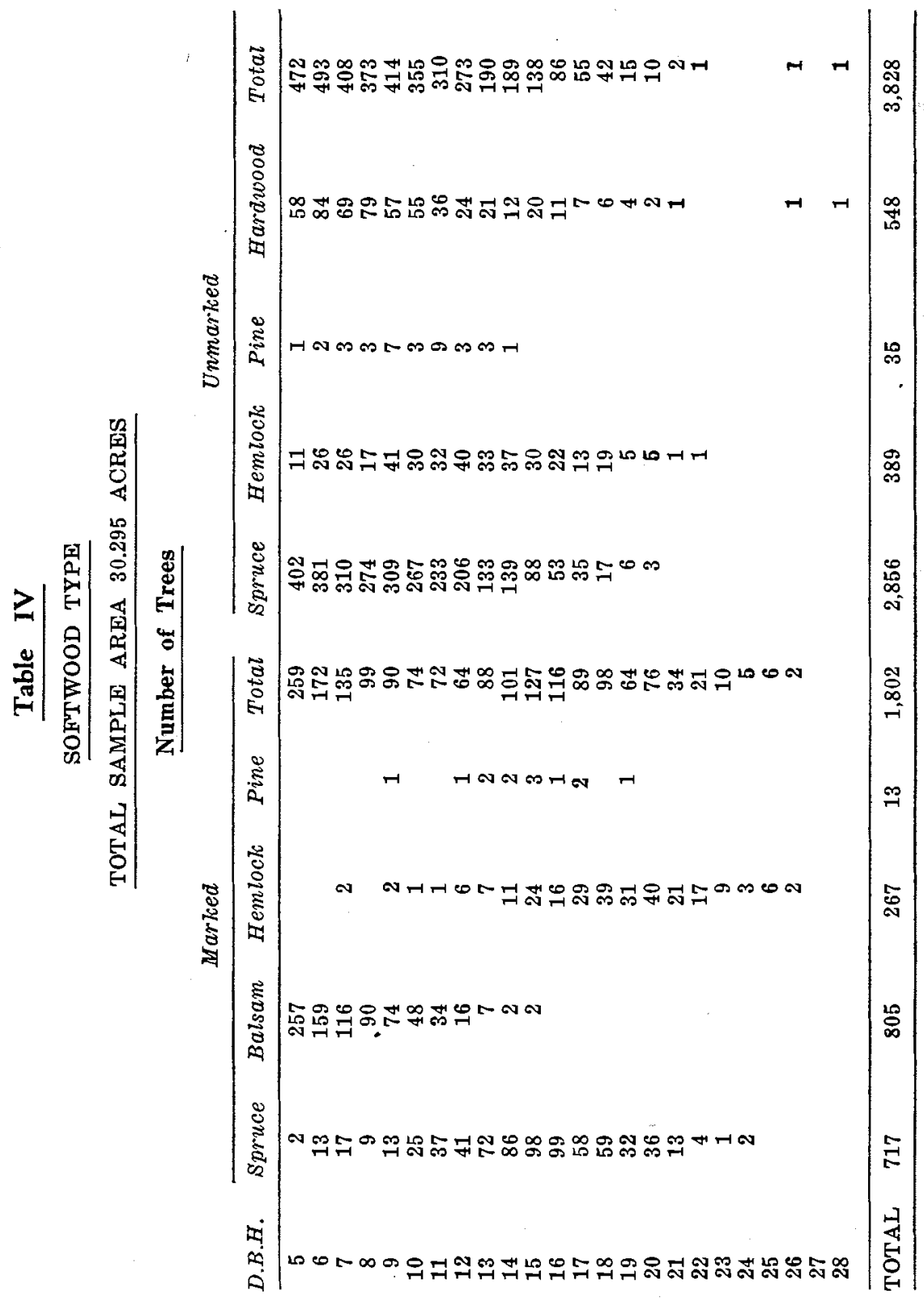


Table VII

YOUNG MIXEDWOOD

TOTAL SAMPLE AREA 0.560 ACRES

Number of Trees

\begin{tabular}{|c|c|c|c|c|c|c|}
\hline \multirow[b]{2}{*}{ D.B.H. } & \multicolumn{3}{|c|}{ Marked } & \multicolumn{3}{|c|}{ Unmarked } \\
\hline & spruce & Balsam & Total & Spruce & Hardwood & Total \\
\hline 5 & & 9 & 9 & 11 & 4 & 15 \\
\hline 6 & 1 & 13 & 14 & 9 & 11 & 20 \\
\hline 7 & & 9 & 9 & 11 & 13 & 24 \\
\hline 8 & & 5 & 5 & 3 & 16 & 19 \\
\hline 9 & 1 & 2 & 3 & 1 & 9 & 10 \\
\hline 10 & & & & 2 & 6 & 8 \\
\hline 11 & & & & & 2 & 2 \\
\hline 12 & & & & & 2 & 2 \\
\hline 13 & & & & & 2 & 2 \\
\hline & 1 & & 1 & 1 & & 1 \\
\hline 15 & 1 & & 1 & & 1 & 1 \\
\hline TOTAL & 4 & 38 & 42 & 38 & 66 & 104 \\
\hline
\end{tabular}

Table VIII

SWAMP TYPE

TOTAL SAMPLE AREA 0.250 ACRES

Number of Trees

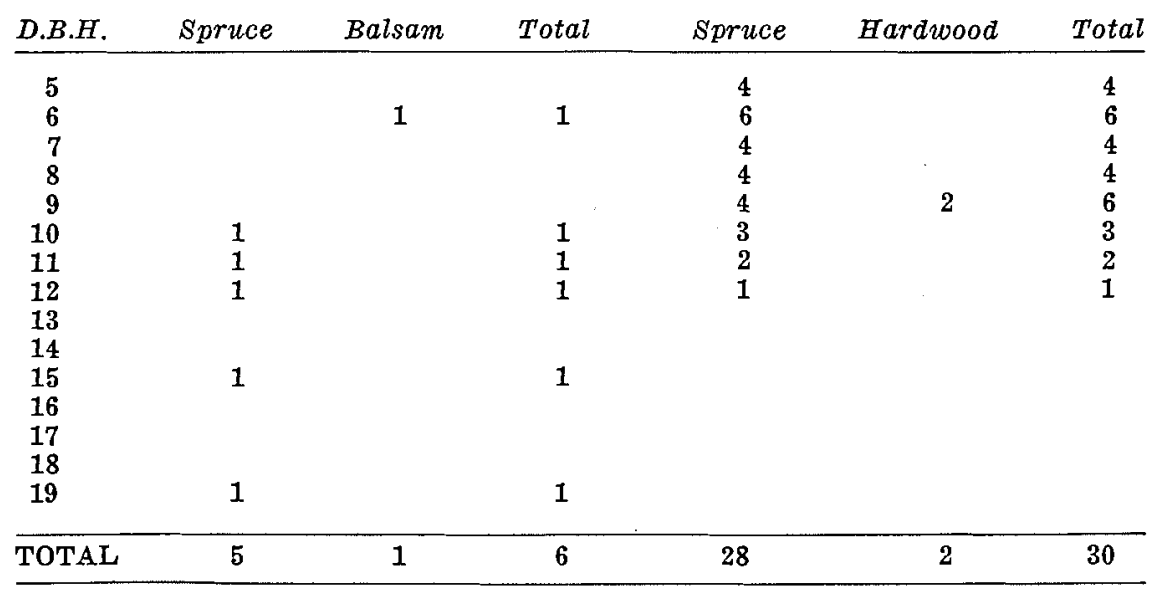


FORESTRY CHRONICLE

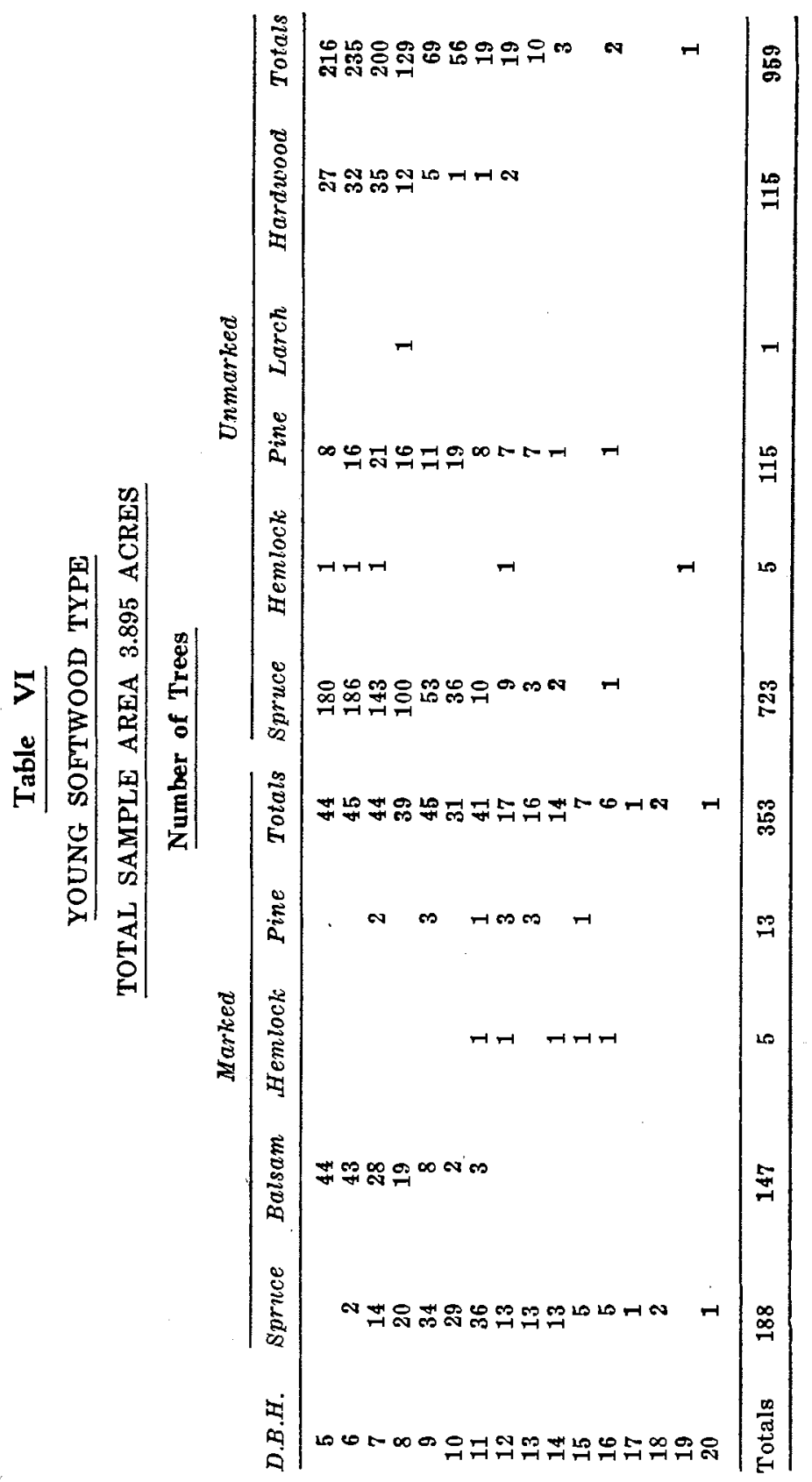




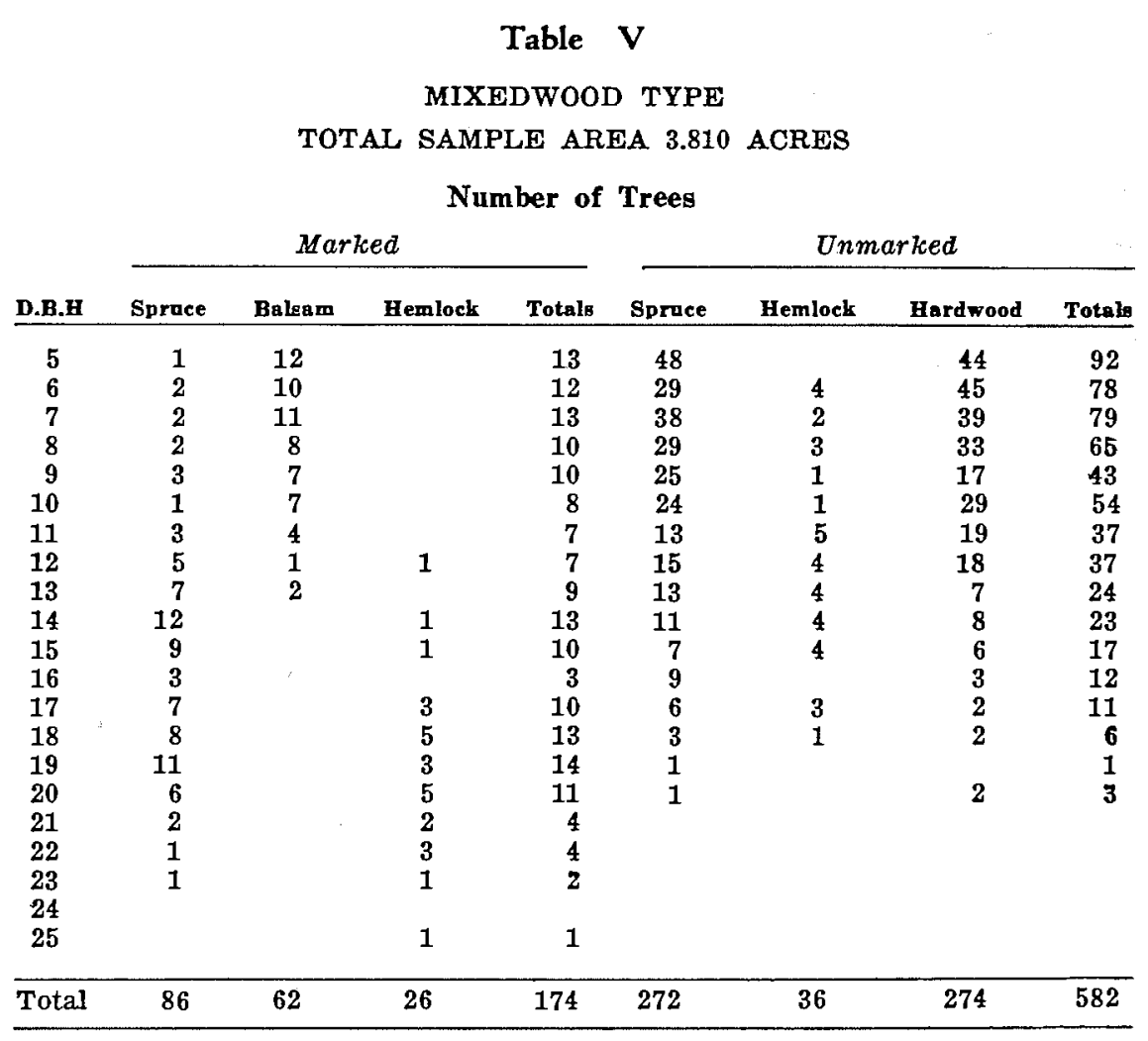

